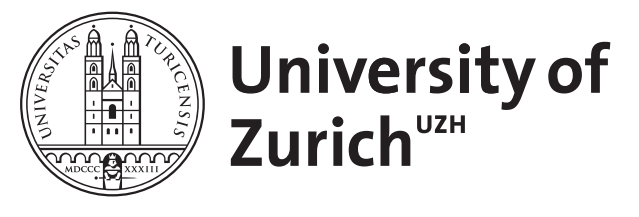

\title{
Endogenous product choice: a progress report
}

Crawford, Gregory S

\begin{abstract}
Empirical models of differentiated product demand are widely used by both academics and practitioners. While these methods treat carefully the potential endogeneity of price, until recently they have assumed the number and characteristics of the products offered by firms are exogenous. This paper presents a progress report on an ongoing research agenda to address this issue. First, it summarizes how the appropriate choice of "orthogonal" instruments can yield consistent estimates of own and cross-price elasticities in the presence of endogenous product characteristics. Second, it summarizes how to measure "quality markups" and the welfare consequences of endogenous product quality in U.S. cable television markets. Related papers and extensions to consider multiple product characteristics and dynamics are also discussed.
\end{abstract}

DOI: https://doi.org/10.1016/j.ijindorg.2011.12.006

Posted at the Zurich Open Repository and Archive, University of Zurich ZORA URL: https://doi.org/10.5167/uzh-174422

Journal Article

Submitted Version

Originally published at:

Crawford, Gregory S (2012). Endogenous product choice: a progress report. International Journal of Industrial Organization, 30(3):315-320.

DOI: https://doi.org/10.1016/j.ijindorg.2011.12.006 


\title{
Endogenous Product Choice: A Progress Report*
}

\author{
Gregory S. Crawford \\ Dept. of Economics \\ University of Warwick
}

This draft: December 18, 2011

\begin{abstract}
Empirical models of differentiated product demand are widely used by both academics and practitioners. While these methods treat carefully the potential endogeneity of price, until recently they have assumed the number and characteristics of the products offered by firms are exogenous. This paper presents a progress report on an ongoing research agenda to address this issue. First, it summarizes how the appropriate choice of "orthogonal" instruments can yield consistent estimates of own and cross-price elasticities in the presence of endogenous product characteristics. Second, it summarizes how to measure "quality markups" and the welfare consequences of endogenous product quality in U.S. cable television markets. Related papers and extensions to consider multiple product characteristics and dynamics are also discussed.
\end{abstract}

*I would like to thank Dan Ackerberg, Jin Hahn, Oleksandr Shcherbakov, and Matthew Shum for their many conversations about the topics surveyed here and Nicola Pavanini and Alessandro Iaria for their research assistance. Any errors are my own. Thanks also to ESRC Grant RES-062-23-2586 for financial support for this research. Correspondence may be sent to Gregory S. Crawford, Department of Economics, University of Warwick, Coventry, CV4 7AL, United Kingdom, phone +44 2476523470 , email crawford@warwick.ac.uk. 


\section{Introduction}

Empirical models of differentiated product demand based on the seminal contributions of Berry (1994) and Berry, Levinsohn and Pakes (1995) (hereafter BLP) are widely used by both academics and practitioners. Berry (1994) introduced methods allowing IV or GMM estimation of demand systems nonlinear in the econometric error using widely available aggregate data on prices, market shares, and products' characteristics across locations or time. This, in turn, opened the door to the specification and estimation of demand models with more flexible econometric specifications than those offered by Logit or Nested Logit models.

BLP popularized parameterizing substitution patterns as a function of products' observed characteristics and the resulting random-coefficients logit (RCL) model is now widely perceived to be the best available option for estimating differentiated product demand systems. Academic applications include the estimation of own- and cross-price elasticities to analyze pricing or to simulate the effects of mergers (Berry et al. (1995), Nevo (2000)), estimating the effects of taxes and quotas (Berry, Levinsohn and Pakes (1999), Griffith, Nesheim and O'Connell (2010)), and measuring the welfare effects of new goods (Petrin (2003)). ${ }^{1}$ Econometric estimation of differentiated product demand models for evaluating the unilateral effects of horizontal mergers (including merger simulation) is also now regularly being used by competition and regulation policymakers (DG Comp (2011)).

While this literature treats carefully the potential endogeneity of price, its vast majority assumes the number and characteristics of the products offered by firms are exogenous. ${ }^{2}$ Indeed, product characteristics are frequently used as instruments for price. While characteristic exogeneity may be reasonable in some settings, as when product choice decisions required fixed investments or commitment on the part of firms, it is likely to be violated in many others. This can have both econometric and economic consequences. Econometrically, endogenous product characteristics imply inconsistency not only for the parameters on the endogenous characteristics, but for all the parameters in the model. Economically, endogenous product characteristics introduce the possibility that market power can influence the offered set and characteristics of products, with associated welfare effects on top of the familiar price effects.

This paper summarizes an ongoing research agenda analyzing consequence of endogenous product characteristics. I first consider settings where the principle focus of the analysis is obtaining the ownand/or cross-price elasticities of demand. This is relevant for issues of optimal pricing for a given set of products or evaluating the short-run price effects of mergers. ${ }^{3}$ In this setting, ongoing research in Ackerberg, Crawford and Hahn (2011) demonstrates how the careful choice of instruments for prices that are orthogonal to potentially endogenous product characteristics can yield consistent estimates of these own- and cross-price elasticities, despite the presence of the endogenous characteristics.

I then consider settings where the choice of characteristics themselves is of interest. Focusing for

\footnotetext{
${ }^{1}$ That is, exogenously provided new goods!

${ }^{2}$ See, e.g., Nevo (2001, p320) and the papers cited there.

${ }^{3}$ Existing merger analysis as practiced by competition policymakers often first considers the price effects of a proposed merger, with product responses by existing firms and/or new entrants providing a secondary, supplementary, analysis. See, e.g., DG Comp (2011, p13) or DOJ/FTC (2010, Secs. 6.1 and 9).
} 
simplicity on an economic environment with a single endogenous characteristic ("quality"), ongoing research in Crawford, Shcherbakov and Shum (2011) endogenizes both the numbers of products and their qualities for U.S. cable television systems. It introduces the concept of a "quality markup" analogous to a price markup and describes how to measure the welfare effects of market power over quality, both in an absolute sense and relative to the conventional effects of market power over price. In two concluding sections, I survey related work in this area and discuss fruitful extensions of the methods applied to date, including allowing for multiple endogenous product characteristics and product choice dynamics.

\section{Benchmark Demand Models}

I introduce two benchmark demand models to motivate the ideas in this paper: a Logit model and a Random Coefficients Logit (RCL) model.

\subsection{A Logit Demand Model}

To fix ideas, consider first a simple Logit version of the canonical differentiated product demand model with a single product characteristic:

$$
\begin{aligned}
u_{i j n} & =\alpha p_{j n}+\beta q_{j n}+\xi_{j n}+\epsilon_{i j n} \\
& =\delta_{j n}+\epsilon_{i j n}
\end{aligned}
$$

where $u_{i j n}$ is the utility to individual $i$ from consuming product $j$ in market $n, p_{j n}$ is the price of that product, $q_{j n}$ is its observed quality, $\xi_{j n}$ is a demand error commonly assumed to be unobserved quality of the product, $\epsilon_{i j n}$ is the idiosyncratic taste of individual $i$ for that product, and $\{\alpha, \beta\}$ are parameters to be estimated. ${ }^{4}$ The second line in (1) aggregates all the elements that are common across individuals into a "mean utility" term, $\delta_{j n}$. Assuming $\epsilon_{i j n}$ is distributed as a Type I Extreme Value yields the conventional Logit market share for $j$ in $n$ :

$$
s_{j n}=\frac{\exp \left(\delta_{j n}\right)}{\sum_{r \in \mathcal{J}_{n}} \exp \left(\delta_{r n}\right)}
$$

where $\mathcal{J}_{n}$ indexes the set of products offered in market $n$, including the outside option, denoted $j=0$. The estimating equation for this model is given by

$$
\begin{aligned}
\log \left(\frac{s_{j n}}{s_{0 n}}\right) & =\delta_{j n} \\
& =\alpha p_{j n}+\beta q_{j n}+\xi_{j n}
\end{aligned}
$$

where $s_{0 n}$ is the market share of the outside good (whose utility has been normalized to zero).

\footnotetext{
${ }^{4}$ Without loss of generality, assume the data have been de-meaned and that a constant term is therefore not necessary.
} 


\section{$2.2 \quad$ A Random Coefficients Logit (RCL) Demand Model}

As discussed above, one of the innovations of Berry and BLP is the ability to consider richer demand specifications like those in a RCL demand model. We extend Equation (1) above by introducing a random coefficient on observed quality:

$$
\begin{aligned}
u_{i j n} & =\alpha p_{j n}+\beta_{i} q_{j n}+\xi_{j n}+\epsilon_{i j n} \\
& =\delta_{j n}+\mu_{i} q_{j n}+\epsilon_{i j n}
\end{aligned}
$$

where $\beta_{i}=\beta+\mu_{i}$ and $\mu_{i} \sim d F\left(\mu_{i} \mid \sigma_{\mu}^{2}\right) \equiv N\left(0, \sigma_{\mu}^{2}\right) .{ }^{5}$ Market shares now require integrating over the distribution of $\mu_{i}$ :

$$
\begin{aligned}
s_{j n}\left(\delta_{n}, q_{n} ; \sigma_{\mu}^{2}\right) & =\int \frac{\exp \left(\delta_{j n}+\mu_{i} q_{j n}\right)}{\sum_{r \in \mathcal{J}_{n}} \exp \left(\delta_{r n}+\mu_{i} q_{r n}\right)} d F\left(\mu_{i} \mid \sigma_{\mu}^{2}\right) \\
& =\int s_{i j n}\left(\delta_{n}, q_{n} ; \mu_{i}\right) d F\left(\mu_{i} \mid \sigma_{\mu}^{2}\right)
\end{aligned}
$$

where $s_{i j n}\left(\delta_{n}, q_{n} ; \mu_{i}\right)$ is the market share for a consumer with random tastes for quality, $\mu_{i}$. The estimating equation for this model is given by

$$
\delta_{j n}\left(s_{n}, q_{n} ; \sigma_{\mu}^{2}\right)=\alpha p_{j n}+\beta q_{j n}+\xi_{j n}
$$

where $s_{n}$ is the set of market shares for all $J_{n}$ products in market $n$ (similarly for $q_{n}$ ) and $\delta_{j n}$ is the mean utility obtained by "inverting" the market share equations in (5) for $j=1, \ldots, J_{n}$ as described in Berry (1994).

\section{Estimating Price Elasticities with Endogenous Product Char- acteristics}

This section summarizes results from Ackerberg, Crawford, and Hahn (2011) (hereafter ACH) to describe how to consistently estimate the price elasticities from models (1)-(3) and (4)-(6) in the presence of a potentially endogenous product characteristic, $q_{j n} \cdot{ }^{6}$ These price elasticities may be of primary importance to an econometric analysis, with any quality elasticity being of secondary importance. $^{7}$

For the Logit model in (1), the own- and cross-price elasticities depend only on observed data $\left(\left\{s_{n}, p_{n}\right\}\right)$ and the price parameter, $\alpha .^{8}$ For the RCL model in (4), ACH show that, similarly, these

\footnotetext{
${ }^{5}$ The normality assumption is for convenience. Any distribution known up to a fixed parameter vector would yield equivalent results.

${ }^{6}$ In what follows, I summarize results for the simple Logit model to motivate the basic intuition of ACH's approach. As discussed there, this approach may be extended to include other exogenous covariates, multiple endogenous characteristics, and non-parametric analysis.

${ }^{7}$ For example, a key element of interest in the evaluation of unilateral competitive effects of a proposed merger is the "diversion ratio," the share of units lost from the sales of one good that go to another good in response to a price change. It is given by the negative of the ratio of the cross-price to the own-price elasticity (Shapiro (1996)).

${ }^{8} \partial \log s_{j n} / \partial \log p_{j n}=\alpha p_{j n}\left(1-s_{j n}\right)$ and $\partial \log s_{j n} / \partial \log p_{k n}=-\alpha p_{k n} s_{k n}$.
} 
elasticities depend only on observed data $\left(\left\{s_{n}, p_{n}, q_{n}\right\}\right)$ and the "price (and nonlinear) parameters," $\alpha$ and $\sigma_{\mu}^{2}$.

The essence of ACH is to show that in fact these "price parameters" can be consistently estimated in the presence of a potentially endogenous product characteristic, $q_{j n}$. The intuition comes from a very simple econometric result. Suppose for the sake of illustration that in equation $(3), p_{j n}$ was exogenous but $q_{j n}$ was not. In this case, it is well known that the OLS estimator for both $\alpha$ and $\beta$ is generally inconsistent: endogeneity bias in any one variable is typically "transmitted" to all the parameter estimates.

Are there any conditions under which we could consistently estimate $\alpha$ in this example? To explore this possibility, partition the econometric error into a portion correlated with the endogenous $q_{j n}$ and a portion which is not:

$$
\begin{aligned}
\xi_{j n} & =q_{j n} \rho+\xi_{j n}^{*} \\
\rho & =\left(E\left[q_{j n} q_{j n}^{\prime}\right]\right)^{-1} E\left[q_{j n} \xi_{j n}\right]
\end{aligned}
$$

where $\rho$ is the population regression coefficient when $\xi_{j n}$ is regressed on $q_{j n}$. By the properties of linear projection, $E\left[q_{j n} \xi_{j n}^{*}\right]=0$ in (7). Using the decomposition in (7), we can rewrite Equation (3) as

$$
\log \left(\frac{s_{j n}}{s_{0 n}}\right)=\alpha p_{j n}+(\beta+\rho) q_{j n}+\xi_{j n}^{*}
$$

This will yield consistent estimates of $\alpha$ and $(\beta+\rho)$, but never $\beta$ alone, whenever $p_{j n}$ and $q_{j n}$ are uncorrelated with $\xi_{j n}^{*}$. By construction, $q_{j n}$ is uncorrelated with $\xi_{j n}^{*} \cdot p_{j n}$ will be as well when

$$
\begin{aligned}
0 & =E\left[p_{j n} \xi_{j n}^{*}\right] \\
& =E\left[p_{j n} \xi_{j n}\right]-E\left[p_{j n} q_{j n}\right] \rho
\end{aligned}
$$

$E\left[p_{j n} \xi_{j n}\right]=0$ by assumption in this motivating example. $E\left[p_{j n} q_{j n}\right] \rho=0$ whenever $p_{j n}$ and $q_{j n}$ are uncorrelated (or orthogonal). ${ }^{9}$ The essence of this example is that any bias induced by the endogeneity of $q_{j n}$ is not transmitted to the price parameter as long as price and quality are uncorrelated.

$\mathrm{ACH}$ show that there is an IV analog to this simple and well-known OLS result. Suppose now $p_{j n}$ and $q_{j n}$ are both endogenous. Further suppose one has an instrumental variable, $z_{j n}$, that is correlated with price and uncorrelated with $\xi_{j n}$. Call such an instrument a "price instrument." $\mathrm{ACH}$ observe, like in the derivation above, that IV estimation of Equation (8) using $z_{j n}$ and $q_{j n}$ as instruments yields consistent estimates of $\alpha$ and $(\beta+\rho)$, but never $\beta$ alone, whenever $z_{j n}$ and $q_{j n}$ are uncorrelated with $\xi_{j n}^{*}$. From (7) above, we know $q_{j n}$ is uncorrelated with $\xi_{j n}^{*}$. $z_{j n}$ will be as well when

$$
\begin{aligned}
0 & =E\left[z_{j n} \xi_{j n}^{*}\right] \\
& =E\left[z_{j n} \xi_{j n}\right]-E\left[z_{j n} q_{j n}\right] \rho
\end{aligned}
$$

\footnotetext{
${ }^{9}$ Or when $\rho=0$, in which case $q_{j n}$ isn't endogenous and we don't have a problem.
} 
$E\left[z_{j n} \xi_{j n}\right]=0$ holds by the assumption that $z_{j n}$ is an appropriate instrument. $E\left[z_{j n} q_{j n}\right] \rho=0$ whenever $z_{j n}$ and $q_{j n}$ are orthogonal. Thus consistent estimates of the "price parameter," $\alpha$, may be obtained if one can identify and select "Orthogonal Instruments," i.e. instruments for price that are uncorrelated with a (potentially) endogenous characteristic.

In the balance of the paper, $\mathrm{ACH}$ demonstrate that this idea has several useful extensions and applications. They show that the same logic demonstrated for the Logit model also applies for the RCL model (though in this case at least two orthogonal instruments are needed), that there is a non-parametric analog to these simple linear results, and that the result can be used to assess the econometric bias induced by potentially endogenous characteristics. They also apply the idea in an application estimating the demand for U.S. cable television services. In their application, they demonstrate that when faced with a selection of possible instruments for price in a simple Logit demand model, the only one that is orthogonal to the quality of offered cable services also yields the smallest estimation bias and the most plausible price elasticities.

\section{The Welfare Effects of Endogenous Quality Choice}

When one is solely interested in the own- and cross-price elasticities arising from a demand model, the analysis summarized above demonstrates that consistent estimation of those is possible in the presence of endogenous product characteristics if one can identify Orthogonal Instruments, instruments for price that are orthogonal to the included endogenous product characteristics. While a useful result, the analysis also demonstrates the inability to consistently estimate own- and cross-quality elasticities, nor make positive or normative statements about the welfare effects of endogenous quality choice. That these are of independent interest demands other methods to address them.

This section summarizes results from Crawford, Shcherbakov, and Shum (2011) (hereafter CSS) that implement an empirical model based on BLP that endogenizes both prices and quality and yields interesting insights into the relative importance for consumer welfare of market power over price versus market power over quality in the study of cable television markets in the U.S. ${ }^{10}$

Models of price and quality choice under single-product monopoly date back at least to Spence (1975). He compares prices and qualities chosen by a single-product monopolist with those offered by a social planner and finds the now-familiar result that a monopolist selects quality to equate the change in the willingness-to-pay (WTP) for the marginal consumer with the change in the marginal cost for a marginal increment in quality. The social planner, on the other hand, equates the change in the WTP for the average consumer with this change in marginal cost. ${ }^{11}$ Whether the social planner or monopolist offers more or less quality depends on two key features of preferences and the monopolist's and social planner's optimal quantities: (1) whether high- or low-WTP consumers

\footnotetext{
${ }^{10}$ The model estimated by CSS differs slightly in its specification of the econometric error of (4) above. To ease the discussion of both papers summarized here, I present it based on on the specification above.

${ }^{11}$ The latter average is taken over the set of consumers that purchase in the social planner outcome. As typical, of course, the social planner prices at marginal cost and the monopolist above.
} 
value more increases in quality and (2) the extent of quantity restriction in monopoly. ${ }^{12}$

Figure 1: Optimal quality choice when the change in WTP decreases vs. increases with quantity
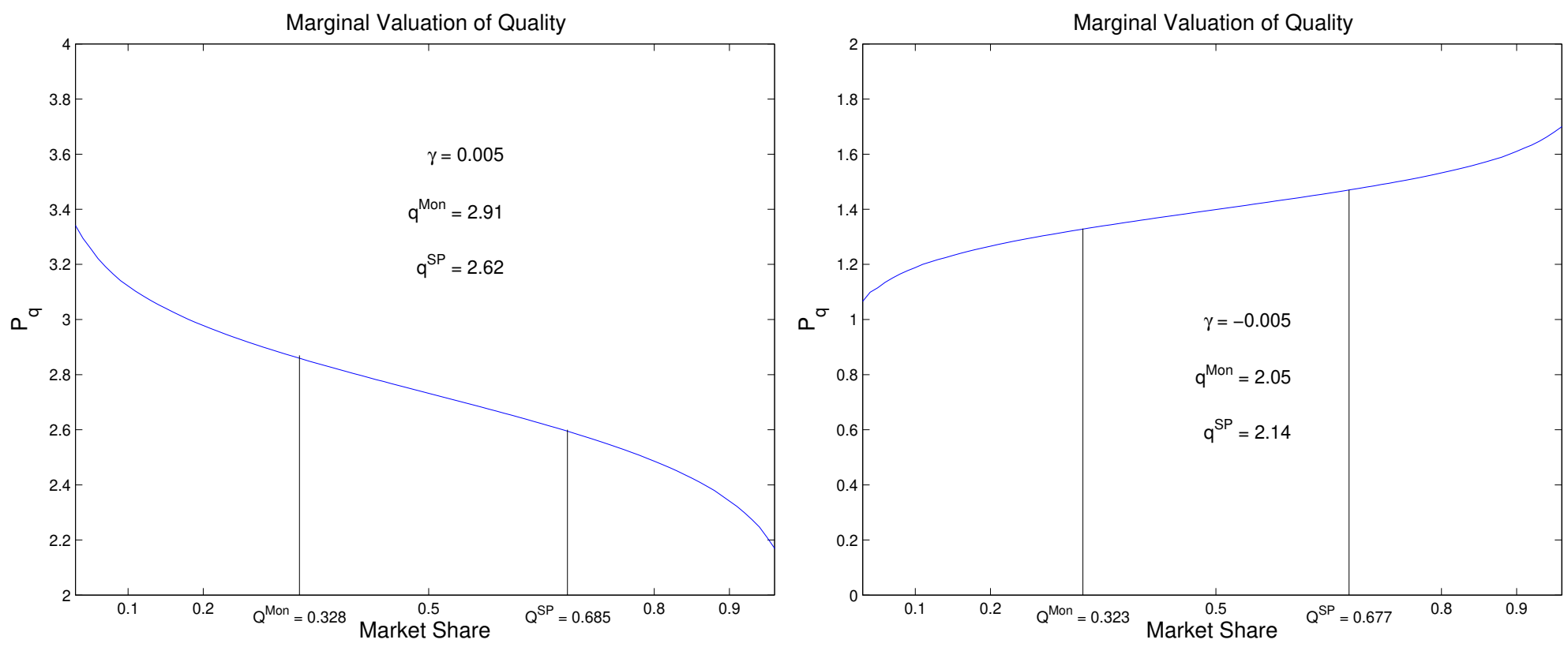

Notes: Reported is the difference in WTP across the demand curve due to a unit increase in quality for a singleproduct logit model given by $\log \left(\frac{s_{j n}}{1-s_{0 n}}\right)=\alpha_{0}+\alpha_{p} p_{j n}+\alpha_{q} q_{j n}+\gamma p_{j n} q_{j n}$. In this setting, positive values of $\gamma($ as in the left panel) mean increasing product quality makes demand curves steeper, while negative values of $\gamma$ (as in the right panel) mean increasing quality makes demand curves flatter.

Figure 1 demonstrates these effects in a simple Logit specification with a price-quality interaction term, $\gamma p_{j n} q_{j n} .{ }^{13}$ Positive values for $\gamma$ mean increments to quality make the demand curve progressively steeper. In this case, described in the left panel of Figure 1, MVQ increases more for high-WTP consumers, the monopolist restricts quantities considerably $\left(Q^{M o n}<<Q^{S P}\right)$, and the monopolist over-provides quality. In the second panel, MVQ increases more for low-WTP consumers and the monopolist still substantially restricts quantities, but he now under-provides quality. Which of the two occurs in practice is, of course, an empirical question.

Models of price and quality choice under multi-product monopoly typically rely on principal-agent models of optimal nonlinear pricing. ${ }^{14}$ Under standard assumptions - a single dimension of heterogeneity and preferences exhibiting single-crossing - the optimal price-quality schedule exhibits features common from screening models: qualities to the highest type maximize social surplus ("no distortion at the top") and qualities for other types are distorted downwards ("quality degradation"). Furthermore, the monopolist's optimum involves a marginal-inframarginal tradeoff: lower-

\footnotetext{
${ }^{12}$ For a Logit model, the monopolist chooses the optimal quality as there is no heterogeneity: the monopolist's marginal consumer has the same preferences as the social planner's average.

${ }^{13}$ See the notes to the figure for details.

${ }^{14}$ These models are conventionally applied to study optimal price-quantity schedules (e.g., Maskin and Riley (1984), Wilson (1993)), but are can equally well be applied to study optimal price-quality schedules (e.g., Mussa and Rosen (1978), Rochet and Stole (2002)).
} 
ing quality to any type at the margin reduces profits (as that type's WTP for quality is generally greater than the monopolist's marginal costs), but allows the monopolist to increase prices for all types choosing higher qualities (because they are all less tempted to switch to the first type's now-lower quality).

The paper in the theory literature most relevant to applying these insights in empirical settings is Rochet and Stole (2002). They analyze the optimal price-quality schedule for a multiproduct monopolist based on the classical screening model of Mussa and Rosen (1978), but add "random participation": the utility to each household for the purchase of any of the quality-differentiated goods depends on the a random-to-the-monopolist error, $\epsilon_{i 0 n}$ :

$$
u_{i j n}=t_{i} q_{j n}-p_{j n}-\epsilon_{i 0 n}
$$

where $t_{i}$ represents individual $i$ 's (money-metric) willingness-to-pay for quality variant, $q_{j n}, p_{j n}$ is the price of that option, and $\epsilon_{i 0 n}$, the random participation term, enters the utility to each good, $j$, due to the standard normalization of utility of the outside good to $0 .{ }^{15}$

The similarities between Equations (4) and (11) were not lost on the latter authors (c.f., Rochet and Stole (2002, p.280)) and the empirical framework used by CSS builds on that foundation. They begin with a specification of preferences similar to that in Equations (4)-(6) above, ${ }^{16}$ but add in a supply-side that leverages the insights of the nonlinear pricing literature.

They assume costs are constant in quantity and involve fixed costs for offering products:

$$
C\left(q_{n}, Q_{n}\right)=\sum_{j \in \mathcal{J}_{n}} m c_{j n}\left(q_{j n}, W_{j n}, \omega_{1 j n}, \omega_{2 j n}\right) Q_{j n}+F_{J_{n} n}
$$

where $Q_{j n}=M_{n} s_{j n}\left(\delta_{n}, q_{n} ; \sigma_{\mu}^{2}\right)$ is the quantity sold for product $j$ in market $n$ (for known market size $\left.M_{n}\right), W_{j n} \equiv\left\{W_{1 j n}, W_{2 j n}\right\}$ are cost shifters, and $F_{J_{n} n}$ are the fixed costs of offering $J_{n}$ services. Marginal costs are given by

$$
m c_{j n}\left(q_{j n}, W_{j n}, \omega_{1 j n}, \omega_{2 j n}\right)=c_{0}+W_{1 j n} \gamma_{1}+\left(c_{1}+W_{2 j n} \gamma_{2}+\omega_{2 j n}\right) q_{j n}+\left(c_{2} / 2\right) q_{j n}^{2}+\omega_{1 j n}
$$

where $\omega_{1 j n}$ captures shocks to marginal quantity costs, $\omega_{2 j n}$ captures shocks to the marginal cost of quality, and $W_{1 j n}, W_{2 j n}$ are (quantity, quality) cost shifters. As they endogenize the choices of prices and qualities, there are two econometric errors per product, the $\omega$, on the supply side.

The balance of the supply side follows naturally. Profits are maximized with respect to both prices and qualities and are given by

$$
\Pi_{n}=\sum_{j \in \mathcal{J}_{n}}\left(p_{j n}-m c_{j n}\right) M_{n} s_{j n}\left(\delta_{n}, q_{n} ; \sigma_{\mu}^{2}\right)-F_{J_{n}} n
$$

\footnotetext{
${ }^{15}$ Rochet and Stole (2002) find that the optimal price-quality schedule with random participation is bounded between the Mussa-Rosen schedule and the first best and that one can get efficiency at the bottom as well as the top (but not the middle).

${ }^{16}$ To fit their application, CSS assume qualities are measured with error and this measurement error takes the place of the structural demand error, $\xi_{j n}$, more commonly used in the literature.
} 
Yielding a system of $2 * J_{n}$ first-order-conditions in each market:

$$
\begin{gathered}
{\left[p_{j n}\right]: \int s_{i j n}\left(\delta_{n}, q_{n} ; \mu_{i}\right) d F\left(\mu_{i} ; \sigma_{\mu}^{2}\right)+\sum_{r \in \mathcal{J}_{n}}\left(p_{r n}-m c_{r n}\right) \int \frac{\partial s_{i r n}\left(\delta_{n}, q_{n} ; \mu_{i}\right)}{\partial p_{j n}} d F\left(\mu_{i} ; \sigma_{\mu}^{2}\right)=0} \\
{\left[q_{j n}\right]:-\frac{\partial m c_{j n}\left(q_{j n}, W_{j n}, \omega_{1 j n}, \omega_{2 j n}\right)}{\partial q_{j n}} \int s_{i j n}\left(\delta, q ; \mu_{i}\right) d F\left(\mu_{i} ; \sigma_{\mu}^{2}\right)+} \\
\sum_{r \in \mathcal{J}_{n}}\left(p_{r n}-m c_{r n}\right) \int \frac{\partial s_{i r n}\left(\delta, q_{n} ; \mu_{i}\right)}{\partial q_{j n}} d F\left(\mu_{i} ; \sigma_{\mu}^{2}\right)=0 .
\end{gathered}
$$

Demand can be estimated separately or jointly with the supply side. Solving for the econometric error on the demand side, $\xi_{j n}$, follows a mild generalization of the Berry inversion described for Equation (6). Solving (15) for the econometric errors on the supply side, $\omega_{1 j n}, \omega_{2 j n}$, is feasible under standard regularity conditions and is done numerically. For a fixed number of products, estimation proceeds using GMM with cost shifters instrumenting for $p_{j n}$ and $q_{j n}$ on the demand side and demand shifters instrumenting for prices, quality, and (quantity and quality) markups in supply. CSS also endogenize the number of products offered in each market.

Quality Markups A primary advantage of endogenizing both prices and qualities is that CSS can measure the welfare consequences of market power over offered qualities. To help do so, they introduce the concept of a "quality markup". Much as a price markup, $p-m c$, measures the difference between the marginal social benefit of an additional unit of quantity $(p)$ with its marginal social cost $(m c)$, a quality markup measures the difference between the marginal social benefit of an additional unit of quality with its marginal social cost.

The total social benefit of any price and quality combination is the sum of profit, given above in (14), and consumers surplus, given by

$$
C S_{n}=-\frac{1}{\alpha} \int \log \left(\sum_{j=0}^{J_{n}} \exp \left(\delta_{j n}\left(s_{n}, q_{n} ; \sigma_{\mu}^{2}\right)+\mu_{i} q_{j n}\right)\right) d F\left(\mu_{i} \mid \sigma_{\mu}^{2}\right)
$$

with partial derivatives

$$
\begin{aligned}
& \frac{\partial C S_{n}}{\partial p_{j n}}=-\int s_{i j n}\left(\delta_{n}, q_{n} ; \mu_{i}\right) d F\left(\mu_{i} \mid \sigma_{\mu}^{2}\right) \\
& \frac{\partial C S_{n}}{\partial q_{j n}}=-\int \frac{\beta+\mu_{i}}{\alpha} s_{i j n}\left(\delta_{n}, q_{n} ; \mu_{i}\right) d F\left(\mu_{i} \mid \sigma_{\mu}^{2}\right)
\end{aligned}
$$

The quality markup is then

$$
\begin{aligned}
\text { Quality Markup } & =M B_{q}-M C_{q} \\
& =\frac{\partial \Pi_{n}}{\partial q_{j n}}+\frac{\partial C S_{n}}{\partial q_{j n}}-\frac{\partial C\left(q_{n}, Q_{n}\right)}{\partial q_{n}}
\end{aligned}
$$

where $M B_{q}$ is the marginal social benefit from a change in quality, $M C_{q}$ is the marginal social cost from such a change, the first two terms in the last line measure $M B_{q}$ and are given in equations (15) and (18) above, and the last term in the last line follows from equation (12). 
There are both similarities and differences between quality and price markups. Both measure the social losses due to market power at the margin and both are (usually) non-zero for a monopolist, but zero for the social planner. Because a monopolist can over-provide quality, however, quality markups can be negative.

The quality markup is useful for quantifying the consequences of market power over quality at the margin. CSS also describe how to measure the consequences of market power over quality for inframarginal consumers as well as the relative importance of market power over price and market power over quality for consumer and social welfare.

Application CSS demonstrate the power of this approach in an application to measure the welfare effects of endogenous quality choice in the market for U.S. cable television services. ${ }^{17}$ This setting is attractive as it fits well the key assumptions underlying the framework. In particular, while cable television systems typically offer multiple products, these products are bundles of television networks such that higher-quality bundles include all the television networks in lower quality bundles and (possibly many) more. A single dimension to product quality is therefore reasonable in this setting. ${ }^{18}$ Furthermore, the model above is a monopoly model of (unregulated) price and quality choice. Before 2000, when regulatory reform leveled the playing field for satellite competitors, the vast majority of U.S. cable systems were unregulated multiproduct monopolists. ${ }^{19}$ After 2000, satellite providers grew in importance, but priced nationally, leaving local cable systems monopolists on their residual demand curve.

In preliminary results, they find modest quality degradation relative to efficient levels for a social planner offering the same number of products and estimated quality markups substantially less than comparable price-cost markups. Despite this, they show that the total welfare effects of market power over quality can be of comparable magnitude to the welfare effects of market power over price.

\section{Related Literature}

Ackerberg, Crawford, and Hahn (2011) and Crawford, Shcherbakov, and Shum (2011) contribute to a small but growing literature that allows for endogenous product choices by firms. This literature can roughly be divided into three branches. The first, earliest, branch searched for reduced-form evidence that the product characteristics offered by firms either were influenced by market power (McManus (2007)) or responded to plausibly exogenous changes in it (Berry and Waldfogel (2001),

\footnotetext{
${ }^{17}$ The CSS approach differs from related work by Chu (2010) by endogenizing the number of products offered by systems, introducing quality markups, and measuring the relative welfare effects of market power over quality versus market power over price.

${ }^{18}$ In practice, CSS use an cost-weighted number of total channels as their quality measure.

${ }^{19}$ An exception applied for the lowest quality product in some markets where local cable franchise authorities were permitted, if they so chose, to regulate cable prices. Crawford and Shum (2007) show this tended to increase the offered quality of such services (but not necessarily reduce their price).
} 
Sweeting (2010)) ${ }^{20}$

Subsequent research has tried to address the consequences of endogenous product choice by following a structural approach: specifying models of demand and supply that allow firms not only to choose prices but also whether and/or what types of products to offer. The two remaining branches of the existing literature differ in the relative weight they put on the "whether" versus "what type" aspects of that decision. In markets where the types of products a firm can offer are discrete, the decision to offer a product or not is conceptually and methodologically similar to the decision to enter a market. Papers in the former literature therefore add profitability conditions familiar from entry models to the standard (demand + pricing) framework to recover the fixed costs of such product introductions. Examples in this vein include Draganska, Mazzeo and Seim (2009), Eizenberg (2011), and Sweeting (2011). ${ }^{21}$

In other settings, the set of products cannot easily be changed (or cannot easily be modeled) and the analysis focuses on the continuous choice of one or more product characteristics. Examples of this type of analysis include Gandhi, Froeb, Tschantz and Werden (2008), Chu (2010), Fan (2010), and Byrne (2011). ${ }^{22}$ A handful of papers, including CSS above and Nosko (2010), combine both of these approaches, endogenizing both the number of products offered and their characteristics. ${ }^{23}$

With a small but growing sample of papers, is there any consensus about the importance of endogenous product choice? With respect to the first branch of the literature, the answer to this is affirmative. There is clear evidence that firms respond to changes in market power by changing product positioning, albeit the magnitudes of these effects are modest. ${ }^{24}$

What then of welfare effects? How important is it to endogenize the products offered or their characteristics to understand the welfare consequences of changes in economic environments? The answers here are mixed. Papers endogenizing product choice using entry methods tend to find relatively

\footnotetext{
${ }^{20}$ McManus (2007) finds evidence of quality distortion for "low-quality" products at speciality coffee shops along the lines predicted by nonlinear pricing models. Berry and Waldfogel (2001) and Sweeting (2010) both examine the consequences of relaxed ownership limits in U.S. radio markets on product variety offered by firms. The former finds evidence of increased numbers of offered formats and formats per station in response to increased concentration in local radio markets while the latter finds, within formats, that commonly owned stations position their playlists to differentiate themselves more from each other and closer to competitors.

${ }^{21}$ Draganska et al. (2009) analyzes the optimal choice of pricing and product assortment within premium vanilla ice creams, Eizenberg (2011) analyzes the optimal pricing and Central Processing Unit (CPU) configurations of PC manufacturers, and Sweeting (2011) analyzes the optimal format choice of radio stations. The last is further discussed below as it offers the only dynamic model in this literature.

${ }^{22}$ Gandhi et al. (2008) offer a numerical analysis of product re-positioning after merger (with fixed numbers of products), Chu (2010) analyzes the price and quality responses of U.S. cable television systems (for their pre-existing products) in response to satellite entry, Fan (2010) predicts how newspapers would change prices to advertisers and multiple continuous quality attributes if challenged mergers had instead been approved, and Byrne (2011) analyzes the price and quality effects of merger in Canadian cable television markets.

${ }^{23}$ Nosko (2010) analyzes the consequences of market power on product line and pricing decisions by PC chip makers.

${ }^{24}$ Berry and Waldfogel (2001) find reducing the number of owners by one in local radio markets increases the number of formats by 0.15 while Sweeting (2010) finds that a common owner increases the proportion of a station's playlist devoted to artists not played on the other station by 7 percentage points (or 13\%) and a common owner increases the proportion of at least one of its stations' playlists devoted to artists who are played by a competitor by 6 percentage points (or 12\%). McManus (2007) finds that among sweet espressos, the highest-priced products, the distortion between estimated marginal benefit and marginal cost is 2.83 cents for the smallest (lowest-quality) cups and 0.23 cents for the largest (highest-quality) cups.
} 
modest effects, albeit that could be a function of the specific settings being analyzed. ${ }^{25}$ Papers allowing continuous characteristic responses, on the other hand, sometimes find larger effects. ${ }^{26}$ Overall, no clear patterns have emerged. Further research, both in other settings and connecting the variation in reported results with the underlying characteristics of the markets under study, would be welcome.

\section{Conclusions}

This paper presents a progress report on an ongoing research agenda to analyze endogenous product choices by firms. It summarizes results developed in Ackerberg, Crawford, and Hahn (2011) that describe how to consistently estimate price elasticities in the presence of potentially endogenous product characteristics and results developed in Crawford, Shcherbakov, and Shum (2011) that endogenize the quality of products offered by U.S. cable television systems and measure the welfare consequences of market power over quality. It also surveys related work in this area.

Understanding the consequences for profitability and welfare of endogenous firm product choices is of first-order importance for both business strategy and public policy. The settings in which models of endogenous product characteristics have been applied is still small and there remains no consensus of the importance of these effects.

From a modelling perspective, endogenizing the discrete decision to offer a product, its continuous characteristics, or both, is likely to be important. Most of the literature has analyzed pricing and characteristic choice in single-characteristic settings. While a reasonable starting point, extending these approaches to accommodate multiple endogenous characteristics (as in Fan (2010)) poses computational hurdles but is critical to estimating realistic models of competitive interaction in most product markets. So, too, are considering the dynamic effects of product choice. While markets differ, in many settings offering new products and/or changing their characteristics is reasonably considered the outcome of a dynamic process, yet only Sweeting (2011) in the literature has taken such an approach. There is much more work to be done.

\footnotetext{
${ }^{25}$ Based on their results, Draganska et al. (2009) simulate the effect of a merger between the two largest ice cream manufacturers and find that incorporating endogenous product choice into the analysis reduces consumer surplus due to decreased variety, but increases consumer surplus due to lower prices at the new varieties. The difference in consumer surplus allowing or not endogenous varieties is slight. Eizenberg (2011) assess the welfare consequences of computer makers being required to offer PC configurations using the oldest chips in the market and finds that the consumer welfare benefits of such a policy was $0.8 \%$. The added fixed costs to firms from the policy meant the bounds on the estimated total surplus included zero, however. Sweeting (2011) finds the introduction of a $10 \%$ royalty rate on music revenues would yield a long-run reduction in the number of radio stations offering musical formats of $11 \%$ and reductions in audience listening of $5.9 \%$.

${ }^{26}$ Gandhi et al. (2008) find in their computational analysis in a Hotelling price and location game that the predicted welfare effects of merger, both on average across consumers and for merging and non-merging firms, can be substantially different when one does and does not allow for endogenous store re-positioning. Fan (2010) predicts much $(25 \%)$ larger price effects allowing for endogenous product responses (that increase offered qualities by as much as $35 \%$ ), albeit the total welfare effect of these changes is comparable to those allowing only price responses. Nosko (2010) finds important effects of competition on the set of chips offered by firms, with half Intel's profit gain from their innovative Core 2 Duo coming from the optimal re-positioning (and pricing) of its products. As described above, Crawford et al. (2011) finds the welfare effects of endogenous quality choice can be of comparable magnitude to that from endogenous pricing.
} 


\section{References}

Ackerberg, D., Gregory S. Crawford, and Jinyong Hahn, "Orthogonal Instruments: Estimating Price Elasticities in the Presence of Endogenous Product Characteristics," 2011. Working Paper, University of Warwick.

Berry, S., "Estimating Discrete Choice Models of Product Differentiation," Rand Journal of Economics, 1994, 25 (2), 242-262.

and J. Waldfogel, "Do Mergers Increase Product Variety? Evidence from Radio Broadcasting," Quarterly Journal of Economics, 2001.

_ _ J. Levinsohn, and A. Pakes, "Voluntary Export Restraints on Automobiles: Evaluating a Trade Policy," American Economics Review, 1999, 89 (3), 400-430.

Berry, Steven, James Levinsohn, and Ariel Pakes, "Automobile Prices in Market Equilibrium," Econometrica, 1995, 63 (4), 841-890.

Byrne, David P., "Consolidation and Price Discrimination in the Cable Television Industry," 2011. Working Paper, University of Melbourne.

Chu, Chenghuan Sean, "The Effects of Satellite Entry on Cable Television Prices and Product Quality," Rand Journal of Economics, 2010, 41 (4), 730-764.

Crawford, G., A. Shcherbakov, and M. Shum, "The Welfare Effects of Endogenous Quality Choice: Evidence from Cable Television Markets," 2011. mimeo, University of Warwick.

Crawford, Gregory S. and Matthew Shum, "Monopoly Quality Degradation in the Cable Television Industry," The Journal of Law and Economics, 2007, 50 (1), 181-219.

DG Comp, "Economic Evidence in Merger Analysis," Technical Report, Directory General for Competition February 2011. Available at http://ec.europa.eu/competition/international/multilateral/2011_feb_economic_evidence.pdf.

DOJ/FTC, Horizontal Merger Guidelines, United States, 2010. Jointly authored by U.S. Department of Justice and Federal Trade Commission. Available at http://www.ftc.gov/os/2010/08/100819hmg.pdf.

Draganska, M., M. Mazzeo, and K. Seim, "Beyond Plain Vanilla: Modeling Joint Product Assortment and Pricing Decisions," Quantitative Marketing and Economics, 2009, 7, 105-146.

Eizenberg, A., "Upstream Innovation and Product Variety in the U.S. Home PC Market," 2011. Working Paper, Hebrew University of Jerusalem.

Fan, Y., "Ownership Consolidation and Product Quality: A Study of the U.S. Daily Newspaper Market," 2010. Working Paper, University of Michigan. 
Gandhi, Amit, Luke Froeb, Steven Tschantz, and Gregory J. Werden, "Post-Merger Product Repositioning," Journal of Industrial Economics, 2008, 56 (1), 49-67.

Griffith, Rachel, Lars Nesheim, and Martin O'Connell, "Sin taxes in differentiated product oligopoly: an application to the butter and margarine market," 2010. CeMMAP Working Paper No. CWP37/10.

Maskin, Eric and John Riley, "Monopoly with Incomplete Information," RAND Journal of Economics, 1984, 15 (2), 171-196.

McManus, Brian, "Nonlinear Pricing in an Oligopoly Market: The Case of Specialty Coffee," Rand Journal of Economics, Summer 2007, 38, 512-532.

Mussa, M. and S. Rosen, "Monopoly and Product Quality," Journal of Economic Theory, 1978, $18(2), 301-17$.

Nevo, A., "Mergers with Differentiated Products: The Case of the Ready-To-Eat Cereal Industry," RAND Journal of Economics, 2000, 31 (3), 395-421.

Nevo, Aviv, "Measuring Market Power in the Ready-To-Eat Cereal Industry," Econometrica, 2001, 69 (2), 307-342.

Nosko, C., "Competition and Quality Choice in the CPU Market," 2010. Working Paper, University of Chicago, Graduate School of Business.

Petrin, Amil, "Quantifying the Benefits of New Products: The Case of the Minivan," Journal of Political Economy, 2003, 110 (4), 705-729.

Rochet, Jean-Charles and Lars A. Stole, "Nonlinear Pricing with Random Participation," Review of Economic Studies, 2002, 69 (1), 277-311.

Shapiro, Carl, "Mergers with Differentiated Products," Antitrust, 1996, pp. 23-30.

Spence, A. M., "Monopoly, Quality, and Regulation," Bell Journal of Economics, 1975, 6 (2), $417-29$.

Sweeting, A., "The Effects of Merger on Product Positioning: Evidence from the Music Radio Industry," Rand Journal of Economics, 2010, 41 (2), 372-97.

— , "Dynamic Product Positioning in Differentiated Product Markets: The Effect of Fees for Musical Performance Rights on the Commercial Radio Industry," 2011. Working Paper, Duke University.

Wilson, R., Nonlinear Pricing, Oxford University Press, 1993. 